\title{
At the End of a Very Hard Day, People Find Some Reason to Believe
}

\footnotetext{
Alzheimer's disease (AD) is recognized in France as a major public health problem and led, beginning in 2001, to the development of three National Alzheimer plans. The third Alzheimer Plan was launched in 2008 (French National Plan for "Alzheimer and Related Disorders" 2008-2012) to strengthen research on $\mathrm{AD}$ and related disorders, promote earlier diagnosis, and improve both patient management and support for caregivers. Research and, in particular, clinical research is one of the central features of the plan. As such, the plan encourages clinical centers belonging to the nationwide network of 27 "Memory Resource And Research Centers" (CMRRs: Centres Mémoire de Ressources et de Recherche) to submit projects focusing on innovative therapeutic work.

The network of CMRRs has been progressively created since the first national plan. Each center has four major missions: 1) diagnosis, follow up, and treatment of patients with $\mathrm{AD}$ and related disorders; 2) teaching; 3 ) direction of the memory center network [1]; and 4) research.

The four articles included in this issue of the Journal of Alzheimer's Disease illustrate some of the research done by the CMRR network [2-5].

Two of these articles deal with the biological aspect of diagnosis and treatment.

In order to evaluate the clinical interest and use of cerebrospinal fluid biomarkers, a data-sharing project, the PLM (Paris-North, Lille, and Montpellier) study, has emerged through collaboration of these three CMRR memory centers. Furthermore, the article of Gabelle and colleagues [2] provides some information about the use of these biomarkers in routine clinical practice in a population of 677 patients.
}

On the therapeutic side, recent results $[6,7]$ have shown some existing but limited effects of pharmacological treatments that are currently available or in development. In this sense, it is important to remain open to other possible treatment options.

A recent study [8] suggested that memory circuits can be modulated by deep brain stimulation (DBS). This technique might be used to slow down cognitive decline in patients suffering from AD. Fontaine and colleagues [3] conducted a prospective study to evaluate the feasibility and safety of DBS in mild AD patients. This pilot study provides new cognitive and behavioral data about the safety of fornix DBS in the hypothalamus but also suggests that the acceptance of DBS by AD patients was low.

In contrast to the previous articles, the remaining two deal with social and non-pharmacological aspects.

Besides the importance of early diagnosis, it is likewise of major interest to provide patients and caregivers with practical information about the disease, diagnosis, and care. This may be done by implementing an integration process through a network of partners involved in elderly care, assistance, or support. This is, in particular, important for case management for elderly in complex situations. The purpose of the Pimouguet et al. article [4] is to describe the main measures from the French national plan that aim to improve the care of dementia patients with an emphasis on MAIA measure (French acronym for Maison pour l'Autonomie et l'Intégration des malades d'Alzheimer / house for the autonomy and integration of patients with Alzheimer's disease). The article summarizes initial results of case management activities in one MAIA in the South West of France and further presents two 
clinical cases benefiting from case management in order to illustrate this type of intervention and its possible benefits.

Furthermore, the French Alzheimer Plan underlines the importance of adapting nursing homes, who usual receive patients at the moderately-severe and severe stages of the disease, to its full extent. In this sense, one of the Plan measure promotes the implementation of new cognitive and behavioral units within nursing homes aimed at receiving patients with behavioral disturbances during the day. From an architectural point of view, these units also need to include a healing garden but does not provide specific recommendations or criteria for implementing such gardens. Rivasseau Jonveaux et al. [5] describes the use of various sources of information (focus groups, surveys of patients, visitors, and caregivers) to characterize the experience and the first assessment done after the creation of one of these gardens.

These articles demonstrate the diversity of clinical research done by the CMRR network. The third national plan was a great opportunity and even though we do not know what the future will bring, it remains important to maintain this research diversity in order to motivate the maximum of clinicians and professionals working in the care of $\mathrm{AD}$ and related disorders patients.

Philippe Robert

President of the French Research Memory Center

Network (FCMRR)

probert@unice.fr

\section{REFERENCES}

[1] Le Duff F, Develay AE, Quetel J, Lafay P, Schück S, Pradier C, Robert P; French National Alzheimer dataBank (BNA)(2012) The 2008-2012 French Alzheimer plan: Description of the national Alzheimer information system. J Alzheimers Dis 29, 891-902.

[2] Gabelle A, Dumurgier J, Vercruysse O, Paquet C, Bombois S, Laplanche J-L, Peoc'h K, Schraen S, Buée L, Pasquier F, Hugon J, Touchon J, Lehmann S (2013) Impact of the 2008-2012 French Alzheimer Plan on the use of cerebrospinal fluid biomarkers in research memory center: The PLM study. J Alzheimers Dis 34, 295-303.

[3] Fontaine D, Deudon A, Lemaire JJ, Razzouk M, Viau P, Darcourt J, Robert P (2013) Symptomatic treatment of memory decline in Alzheimer's disease by deep brain stimulation: A feasibility study. J Alzheimers Dis 34, 313-321.

[4] Pimouguet C, Bassi V, Somme D, Lavallart B, Helmer C, Dartigues JF (2013). The 2008-2012 French Alzheimer Plan: A unique opportunity for improving integrated care for dementia. J Alzheimers Dis 34, 305-312.

[5] Rivasseau Jonveaux T, Batt M, Fescharek R, Benetos A, Trognon A, Bah Chuzeville S, Pop A, Jacob C, Yzoard M, Demarche L, Soulon L, Malerba G, Bouvel B (2013) Healing gardens and cognitive behavioral units in the management of Alzheimer's disease patients: The Nancy experience. J Alzheimers Dis 34, 323-336.

[6] Scheltens P, Sperling R, Salloway S, Fox N (2012) Bapineuzumab IV Phase 3 results. J Nutr Health Agin 16, 797.

[7] Doody RS (2012) Results of immune-based trials in neurological disorders Phase 3 studies of Solanezumab for mild to moderate Alzheimer's disease. 137th Annual Meeting of the American Neurological Association, p. 31; http://www.aneuroa.org/files/ 2012\%20Annual\%20Meeting/ANA2012OnsiteProgram.pdf

[8] Laxton AW, Tang-Wai DF, McAndrews MP, Zumsteg D, Wennberg R, Keren R, Wherrett J, Naglie G, Hamani C, Smith GS, Lozano AM (2012) A phase I trial of deep brain stimulation of memory circuits in Alzheimer's disease. Ann Neurol 68, 521-534. 